Pacific Journal of Mathematic 


\title{
LATTICES OF HAUSDORFF COMPACTIFICATIONS OF A LOCALLY COMPACT SPACE
}

\author{
V. KANNAN AND T. THRIVIKRAMAN
}

This paper gives a lattice theoretic characterization of (complete) lattices which are lattices of Hausdorff compactifications of locally compact spaces. This is accomplished via a characterization of the lattices of closed equivalence relations on $T_{1}$ spaces.

Notations. $L$ is a complete dually atomic lattice.

$D$ is the set of all dual atoms of $L$.

1. Definition. Let $p \in L$. Then the set $H(p)=\{d \in D \mid d \geqq p\}$ is called the hull of $p$.

NoTE. $H(1)=\varnothing$.

2. Definition. Let $E \subset D$. The kernel of $E$ denoted by Ker $E$ is defined as $\Lambda_{d \in E} d$.

3. Definition. Let $p \in L . \quad p$ is said to be a primary element if whenever $q$ and $r$ are two elements in $H(p)$ such that Card. $H(q \wedge r) \neq 3$ and $s \in D$ is such that Card. $H(s \wedge q)=3=$ Card. $H(s \wedge r)$, it is true that $s \in H(p)$.

Note. Trivially, 1 as well as any dual atom is primary.

4. Definition. A star of $L$ is defined as a subset $S$ of $D$ which is maximal with respect to the following property: $d, d^{\prime} \in S \Rightarrow$ $d \wedge d^{\prime}$ is a primary element and if $\left(d, d^{\prime}\right)$ and $\left(d_{1}, d_{2}\right)$ are distinct pairs of elements of $S$, then $d \wedge d^{\prime} \neq d_{1} \wedge d_{2}$.

5. Definition. Let $p, q$ be primary elements. Then a primary rectangle is defined as $H(p, q)=\left\{\left(S_{1}, S_{2}\right) \mid S_{1}, S_{2}\right.$ are stars such that $\left.S_{1} \cap H(p) \neq \varnothing \neq S_{2} \cap H(q)\right\}$.

6. Definition. Let $A \subset D . \quad \alpha(A)$ is defined as the set of all unordered pairs $\left(S, S^{\prime}\right)$ of stars such that $S \cap S^{\prime} \cap A \neq \varnothing$.

7. Theorem. A complete, dually atomic lattice $L$ is isomorphic to the lattice of closed equivalence relations of a $T_{1}$ space $X$ if and 
only if the following are true:

(i) $\mathbf{V}_{i \in J} p_{i}$ is a primary element for any collection $\left\{p_{i} \mid i \in J\right\}$ of primary element in $L$.

(ii) (a) If $d \in D$, then $d$ belongs to exactly two stars.

(b) Any two stars intersect in a singleton.

(iii) $H \subset D$ is a hull if and only if

(a) if $d_{1}, d_{2} \in H$ and if $d \in D$ such that $d \geqq d_{1} \wedge d_{2}$, then $d \in H$.

(b) $\alpha(H)$ is an intersection of finite unions of primary rectangles.

(iv) $a=\operatorname{Ker}(H(a))$ for every $a \in L$.

Proof (Necessity). Easily checked, bearing in mind the discussion in $\S 1$ of [3].

(Sufficiency). Let $X$ be the set of all stars in $L$. From (ii) (a) and (ii) (b), there exists a bijection $\theta$ between the set $D$ of all dual atoms of $L$ and the set of all unordered pairs of distinct stars.

From (i), and noticing that $0 \in L$ is a primary element, it follows that primary elements of $L$ form a complete lattice $P$ under the same order. Now $D$ is precisely the set of all dual atoms of $P$. We can form the hull-kernel topology for $D$ in the lattice. This topology can then be translated to $X$ as follows:

A set $A \subset X$ is closed if and only if $\theta^{-1}(A \times A)$ is a hull of a member of $P$. We show now that this defines a $T_{1}$ topology on $X$. Clearly $\theta^{-1}(\varnothing \times \varnothing)=\varnothing$ and $\theta^{-1}(X \times X)=D$ so that $\varnothing$ and $X$ are closed. If $S \in X$, then $\theta^{-1}(\{S\} \times\{S\})=\varnothing=H(1)$ so that every singleton is closed. If $S \neq S^{\prime}, S, S^{\prime} \subset X, \theta^{-1}\left(\{S\} \times\left\{S^{\prime}\right\}\right)$ is a singleton. So any two-element set is closed.

Now let $A, B \subset X$ be closed, each containing at least two elements. Then $A \cup B$ is closed. For, let $p$ and $q$ be the primary elements determined by $A$ and $B$ respectively. Then consider the primary rectanglls $H(p, p), H(q, q), H(p, q), H(q, p)$. Now if $C=\theta^{-1}((A \cup B) \times$ $(A \cup B)$ ), then $\alpha(C)$ is the union of these primary rectangles. For, if $\left(S, S^{\prime}\right) \in \alpha(C)$, then there exists $d \in C$ such that $S \cap S^{\prime}=\{d\}$; now $\theta(d)=\left(S, S^{\prime}\right) \in((A \cup B) \times(A \cup B))$ so that $S, S^{\prime} \in A \cup B$; it is easy to check that if $S, S^{\prime}$ both belong to $A$ (respectively $B$ ), then $\left(S, S^{\prime}\right) \in$ $H(p, p)$ (respectively $H(q, q)$ ). If $S \in A$ and $S^{\prime} \in B$, then $\left(S, S^{\prime}\right) \in H(p, q)$ and if $S \in B$ and $S^{\prime} \in A$, then $\left(S, S^{\prime}\right) \in H(q, p)$. On the other hand, that all these four primary rectangles are subsets of $\alpha(C)$ is easily verified.

Hence by condition (iii), $C$ is a hull set. Note that condition (iii) (a) is satisfied here, by the maximality in the definition of stars.

Let $K$ be the kernel of $C$. It can be seen that $K$ is primary. It follows that $A \cup B$ is closed.

Let $A_{i} \subset X$ be closed for every $i \in J$ and let $A=\bigcap A_{i}$. Then 
$\theta^{-1}(A \times A)$ is the intersection $\cap \theta^{-1}\left(A_{i} \times A_{i}\right)$ and so is a hull set. For, by condition (iii), intersection of hull sets is again a hull set. Let $r$ be its kernel. Then by using condition (iv), it can be proved that $r=\vee p_{i}$ where $p_{i}$ is the primary element corresponding to $A_{i}$. So it follows from condition (i) that $r$ is primary. So $A$ is closed. Thus $X$ is a $T_{1}$ space.

Next we show that $L$ is isomorphic to $L(X)$, the lattice of closed equivalence relations for this space $X$. Let us define a map $\eta: L \rightarrow$ $L(X)$ as follows: If $x \in L, \eta(x)$ is the relation defined on $X$ as below: $S_{1} \eta(x) S_{2}$ if and only if either $S_{1}=S_{2}$ or $S_{1} \cap S_{2} \cap H(x) \neq \varnothing$. This is an equivalence relation. For, let $S_{1} \eta(x) S_{2}$ and $S_{2} \eta(x) S_{3}$; also let $S_{1} \cap S_{2}=\left\{d_{3}\right\}, S_{2} \cap S_{3}=\left\{d_{1}\right\}$, and $S_{3} \cap S_{1}=\left\{d_{2}\right\}$; then by the maximality in the definition of stars, it can be proved that $d_{2} \geqq d_{1} \wedge d_{3}$ and so by (iii) (a), $d_{2} \in H(x)$ since $H(x)$ is a hull set. So $S_{1} \eta(x) S_{3}$. Thus transitivity is proved. Reflexivity and symmetry of $\eta(x)$ are trivial.

Now we show that $\eta(x) \in L(X)$. That is, $\eta(x)$ is a closed equivalence relation on $X$. The relation $\eta(x)$ viewed as a subset of $X \times X$ is precisely $\alpha(H(x))$. So by (iii)(b), it is an intersection of finite union of primary rectangles. Each primary rectangle is a closed subset of $X \times X$ since $H(p, q)=A \times B$ where $A$ and $B$ are the closed subsets of $X$ determined by $p$ and $q$ respectively. So $\eta(x)$ is a closed subset of $X \times X$.

Thus $\eta: L \rightarrow L(X)$ is well defined.

Now $\eta$ is injective. For, let $x \neq y$. Then by condition (iv) we get that $H(x) \neq H(y)$. Let $d \in H(x)-H(y)$ (say). Let $S, S^{\prime}$ be the two stars containing $d$. Then $\left(S, S^{\prime}\right) \in \alpha(H(x))$ but $\notin \alpha(H(y))$. So $\eta(x) \neq \eta(y)$. Futher $\eta$ is surjective. For, let $R$ be a closed equivalence relation on $X$. Then $R$ is an intersection of finite unions of closed rectangles, whereas each closed rectangle is a primary rectangle. Let $H=\left\{d \in D \mid\right.$ the pair $\left(S_{1}, S_{2}\right)$ of stars containing $d$ belongs to $\left.R\right\}$. Then $H$ satisfies conditions (iii) (a) and (iii) (b) and hence by (iii), $H$ is a hull set. If $x$ is its kernel, it follows that $\eta(x)=R$.

$\eta$ preserves arbitrary unions. For, let $x=\mathrm{V}_{\alpha} x_{\alpha}$. Now $\cap H\left(x_{\alpha}\right)$ is a hull set by (iii). It ought to contain $H(x)$. Let $y$ be its kernel. Then $y \geqq x_{\alpha}$ for each $\alpha$. So $y \geqq x$. Therefore, $H(y) \subset H(x)$. So $\eta(y)=\eta(x)$. But $\eta(y)=\mathrm{V}_{\alpha} \eta\left(x_{\alpha}\right)$ since it can be easily seen that $S_{1} \bigvee_{\eta}\left(x_{\alpha}\right) S_{2}$ if and only if $S_{1} \cap S_{2} \cap\left(\cap H\left(x_{\alpha}\right)\right) \neq \varnothing$, while $\cap H\left(x_{\alpha}\right)=H(y)$.

$\eta$ preserves intersections. This can be seen as in the case of unions, by considering the union of the hulls.

Thus $\eta$ is an isomorphism.

Thus sufficiency is proved.

8. THeOREM. Let $L$ be a complete, dually atomic lattice. Then $L$ is the lattice of $T_{2}$ compactifications of a locally compact space if 
and only if it satisfies conditions (i) through (iv) above and also:

(v) Given any two primary elements $p_{1}, p_{2} \in L$, there exist primary elements $q_{1}, q_{2} \in L$ such that $p_{1} \vee q_{1}=p_{2} \vee q_{2}=1$ and $q_{1} \wedge q_{2}=0$.

(vi) Given any collection of primary elements $\left\{p_{\alpha}\right\}_{\alpha \in J}$ such that $\bigwedge_{\alpha \in K} p_{\alpha}$ is a primary element for any finite subset $K$ of $J$, then $\Lambda_{\alpha \in J} p_{\alpha}$ is also a primary element.

Proof. Notice that (v) is equivalent to saying that the space $X$ uniquely specified by $L$, is normal.

Also (vi) is equivalent to compactness.

It can be proved that the lattice of all closed equivalence relations of $\beta X-X$ is isomorphic to the lattice of all Hausdorff compactifications of $X$, when $X$ is locally compact and Hausdorff.

Thus the theorem.

9. REMARK. When $X$ is not locally compact, the upper semilattice $K(X)$ of all Hausdorff compactifications of $X$ is not necessarily a lattice (cf. [5]). Now the problem arises whether the semilattice $K(X)$ determines the space $\beta X-X$. When $X$ is locally compact, the answer is in the affirmative (cf. [1]). A method to construct the space $\beta X-X$ from $K(X)$ is given in [2]. But when $x$ is not locally compact, $K(X)$ does not determine $\beta X-X$ (cf. [2]). A study in this direction forms a part of [4].

\section{REFERENCES}

1. K. D. Magill, Jr., The lattice of compactifications of a locally compact space, Proc. London Math. Soc., 18 (1968), 231-244.

2. T. Thrivikraman, On compactifications of Tychonoff spaces, Yokohama Math. J., 20 (1972), 99-106.

3. - On Hausdorff quotients of spaces and Magill's theorem, Monat. für-Math., 76 (1972), 345-355.

4. - Studies in Compactifications and Other Extensions, Doctoral Thesis submitted to Madurai University, July, 1971.

5. J. Visliseni and J. Flachsmeyer, The power and structure of the lattice of all compactifications of a completely regular space, Doklady Nauk SSSR (N. S.), 165 (1965), 1423-1425.

Received July 16, 1973 and in revised form April 30, 1974.

Madurai University, Madurai-21

AND

Mar Athanastus College, Kothamangalam, Kerala, India 


\section{PACIFIC JOURNAL OF MATHEMATICS}

\section{EDITORS}

RICHARD ARENS (Managing Editor)

University of California

Los Angeles, California 90024

\section{J. DugundJI}

Department of Mathematics University of Southern California Los Angeles, California 90007

D. Gilbarg and J. Milgram

Stanford University

Stanford, California 94305
University of Washington Seattle, Washington 98105

\section{ASSOCIATE EDITORS}
E. F. BECKENBACH
B. H. NeumanN
F. WolF
K. YoShIDA

\section{SUPPORTING INSTITUTIONS}

\author{
UNIVERSITY OF SOUTHERN CALIFORNIA \\ STANFORD UNIVERSITY \\ UNIVERSITY OF TOKYO \\ UNIVERSITY OF UTAH \\ WASHINGTON STATE UNIVERSITY \\ UNIVERSITY OF WASHINGTON \\ $\stackrel{*}{*} \stackrel{*}{*} \stackrel{*}{ }{ }^{*}$ AMERICAN MATHEMATICAL SOCIETY
}

The Supporting Institutions listed above contribute to the cost of publication of this Journal, but they are not owners or publishers and have no responsibility for its content or policies.

Mathematical papers intended for publication in the Pacific Journal of Mathematics should be in typed form or offset-reproduced, (not dittoed), double spaced with large margins. Underline Greek letters in red, German in green, and script in blue. The first paragraph or two must be capable of being used separately as a synopsis of the entire paper. Items of the bibliography should not be cited there unless absolutely necessary, in which case they must be identified by author and Journal, rather than by item number. Manuscripts, in triplicate, may be sent to any one of the editors. Please classify according to the scheme of Math. Reviews, Index to Vol. 39. All other communications should be addressed to the managing editor, or Elaine Barth, University of California, Los Angeles, California, 90024.

The Pacific Journal of Mathematics expects the author's institution to pay page charges, and reserves the right to delay publication for nonpayment of charges in case of financial emergency.

100 reprints are provided free for each article, only if page charges have been substantially paid. Additional copies may be obtained at cost in multiples of 50 .

The Pacific Journal of Mathematics is issued monthly as of January 1966. Regular subscription rate: $\$ 72.00$ a year (6 Vols., 12 issues). Special rate: $\$ 36.00$ a year to individual members of supporting institutions.

Subscriptions, orders for back numbers, and changes of address should be sent to Pacific Journal of Mathematics, 103 Highland Boulevard, Berkeley, California, 94708.

\section{PUBLISHED BY PACIFIC JOURNAL OF MATHEMATICS, A NON-PROFIT CORPORATION}

Printed at Kokusai Bunken Insatsusha (International Academic Printing Co., Ltd.), 270, 3-chome Totsuka-cho, Shinjuku-ku, Tokyo 160, Japan.

\section{Copyright (C) 1975 by Pacific Journal of Mathematics} Manufactured and first issued in Japan 


\section{Pacific Journal of Mathematics}

\section{Vol. 57, No. $2 \quad$ February, 1975}

Norman Larrabee Alling, On Cauchy's theorem for real algebraic curves with boundary .......

Daniel D. Anderson, A remark on the lattice of ideals of a Prüfer domain ..................

Dennis Neal Barr and Peter D. Miletta, A necessary and sufficient condition for uniqueness of

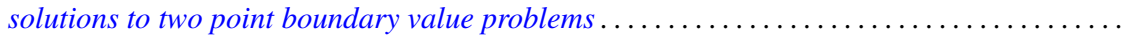

Ladislav Beran, On solvability of generalized orthomodular lattices . . . . . . . . . . ........

L. Carlitz, A three-term relation for some sums related to Dedekind sums . . . . . . . . . .....

Arthur Herbert Copeland, Jr. and Albert Oscar Shar, Images and pre-images of localization

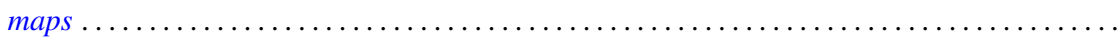

G. G. Dandapat, John L. Hunsucker and Carl Pomerance, Some new results on odd perfect

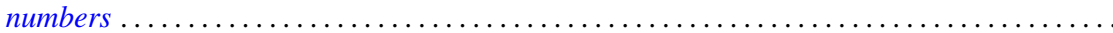

M. Edelstein and L. Keener, Characterizations of infinite-dimensional and nonreflexive

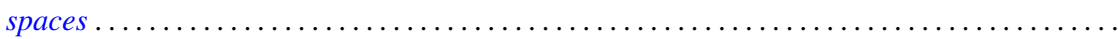

Francis James Flanigan, On Levi factors of derivation algebras and the radical embedding

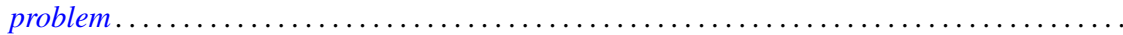

Harvey Friedman, Provable equality in primitive recursive arithmetic with and without

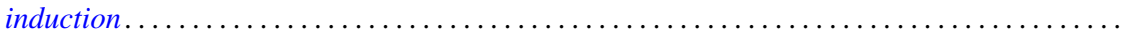

Joseph Braucher Fugate and Lee K. Mohler, The fixed point property for tree-like continua with

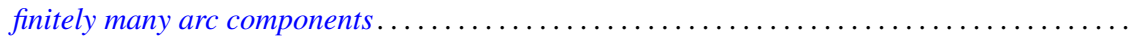

John Norman Ginsburg and Victor Harold Saks, Some applications of ultrafilters in

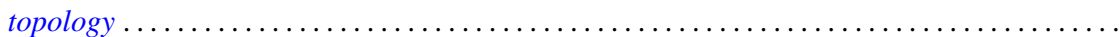

Arjun K. Gupta, Generalisation of a "square" functional equation .....................

Thomas Lee Hayden and Frank Jones Massey, Nonlinear holomorphic semigroups ..........

V. Kannan and Thekkedath Thrivikraman, Lattices of Hausdorff compactifications of a locally

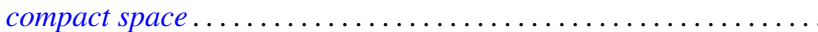

J. E. Kerlin and Wilfred Dennis Pepe, Norm decreasing homomorphisms between group



Young K. Kwon, Behavior of $\Phi$-bounded harmonic functions at the Wiener boundary ...

Richard Arthur Levaro, Projective quasi-coherent sheaves of modules .

Chung Lin, Rearranging Fourier transforms on groups...........................

David Lowell Lovelady, An asymptotic analysis of an odd order linear differential equation . . 4475

Jerry Malzan, On groups with a single involution .......................... 481

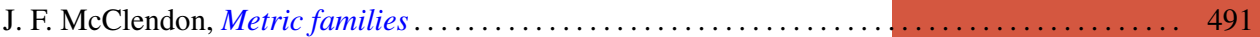

Carl Pomerance, On multiply perfect numbers with a special property .

Mohan S. Putcha and Adil Mohamed Yaqub, Polynomial constraints for finiteness of semisimple rings. .

Calvin R. Putnam, Hyponormal contractions and strong power convergence . . . . . . . . . 531

Douglas Conner Ravenel, Multiplicative operations in $\mathrm{BP} * \mathrm{BP} \ldots \ldots \ldots \ldots \ldots \ldots \ldots \ldots \ldots .539$

Judith Roitman, Attaining the spread at cardinals which are not strong limits . . . . . . . . . 545

Kazuyuki Saitô, Groups of *-automorphisms and invariant maps of von Neumann algebras . . . 553

Brian Kirkwood Schmidt, Homotopy invariance of contravariant functors acting on smooth

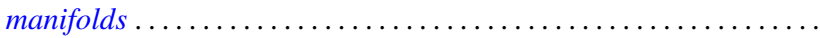

Kenneth Barry Stolarsky, The sum of the distances to $N$ points on a sphere.

Mark Lawrence Teply, Semiprime rings with the singular splitting property.

J. Pelham Thomas, Maximal connected Hausdorff spaces..............

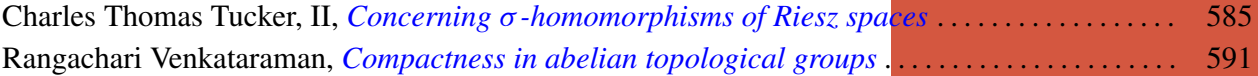

William Charles Waterhouse, Basically bounded functors and flat sheaves . . . . . . . . . . . 597

David Westreich, Bifurcation of operator equations with unbounded linearized part ......... 611

William Robin Zame, Extendibility, boundedness and sequential convergence in spaces of 